\title{
Chantal Lapeyre-Desmaison, Pascal Quignard. La voix de la danse
}

\section{Stefano Genetti}

\section{(2) OpenEdition \\ 1 Journals}

\section{Edizione digitale}

URL: http://journals.openedition.org/studifrancesi/2292

DOI: 10.4000/studifrancesi.2292

ISSN: 2421-5856

\section{Editore}

Rosenberg \& Sellier

\section{Edizione cartacea}

Data di pubblicazione: 1 aprile 2014

Paginazione: 189

ISSN: 0039-2944

\section{Notizia bibliografica digitale}

Stefano Genetti, «Chantal Lapeyre-Desmaison, Pascal Quignard. La voix de la danse », Studi Francesi [Online], 172 (LVIII | I) | 2014, online dal 01 avril 2014, consultato il 18 septembre 2020. URL : http:// journals.openedition.org/studifrancesi/2292 ; DOI : https://doi.org/10.4000/studifrancesi.2292

Questo documento è stato generato automaticamente il 18 settembre 2020.

\section{(c) (i) (9)}

Studi Francesi è distribuita con Licenza Creative Commons Attribuzione - Non commerciale - Non opere derivate 4.0 Internazionale. 


\title{
Chantal Lapeyre-Desmaison, Pascal Quignard. La voix de la danse
}

\author{
Stefano Genetti
}

\section{NOTIZIA}

CHANTAL LAPEYRE-DESMAIson, Pascal Quignard. La voix de la danse, Villeneuve d'Ascq, Presses Universitaires du Septentrion, 2013, pp. 171.

1 Tre mesi dopo la pubblicazione del presente saggio è apparso il libro L'Origine de la danse (Galilée, 2013) dove Pascal Quignard prolunga e approfondisce il proprio pensiero della danza sulla scia della sua recente collaborazione, in occasione dello spettacolo Medea, con Carlotta Ikeda, esponente di spicco della danza butoh. Affermatosi in Giappone sul finire degli anni Cinquanta, il butoh ha profondamente influenzato la scena contemporanea occidentale: danza regressiva, della lentezza e della metamorfosi, animalesca leçon de ténèbres sospesa tra nascita e morte, essa si rivela quanto mai affine all'immaginario di Quignard. Ciò a testimonianza della centralità che il motivo della danza - a un tempo immagine e spunto di meditazione - ha assunto nella sua scrittura riversandosi periodicamente in attività al fianco di coreografi e performers quali Philippe Saire, Angelin Preljocaj e, da ultima, Andrea Sitter (Obstinés lambeaux d'images, La Briqueterie di Vitry-sur-Seine, 30 maggio 2013).

2 In estrema sintesi, nel presente volume l'A., che di Quignard è una delle maggiori specialiste, riattraversa l'opera alla luce della propria esperienza, intesa anche come pratica, della danza. Muovendo dalla rivisitazione del mito di Medea cui si è accennato e ad essa ritornando, rende conto della visione radicalmente interartistica del fare letterario perseguita da Quignard e documentata in molti suoi testi, da Inter aerias fagos o Le Nom sur le bout de la langue fino a Pour trouver les enfers o Requiem. Moltiplicando i riferimenti teorici - all'Anthropologie du geste di Marcel Jousse, in particolare - l'A. intesse un efficace reticolo di letture ravvicinate, spesso incentrate su testi poco commentati quali Le Petit Cupidon e Le Triomphe du temps. Se in Boutès vede un traité sulla 
danza in quanto risposta all'appello della musica, che è un rappel della voce perduta $\mathrm{e}$ un richiamo all'origine, più in generale ella interroga il nesso tra corpo e lettera, tra tracciato coreografico e calligrafico, e indaga il movimento della creazione tra assenza al mondo e abbandono di sé, da un lato e, dall'altro, presentimento e surgissement di una presenza. Anche al di là dell'investimento del corpo nell'atto di scrivere, individua nella scrittura - gesto e desiderio di una revenance - il riemergere del corpo deterritorializzato e occultato, sottoposto all'ortopedia del linguaggio. Nella voce sacrificata della scrittura rinviene insomma la voce della danza: «voix muette du corps, prééminence du geste et du mouvement sur l'intention de signification» (p. 100), nonché cifra di tutta una «poétique du corps sensoriel» (p. 47)

3 L'A. offre così un approccio pertinente e originale a un'opera tra le più studiate nel panorama letterario francese contemporaneo, come attestano la recente monografia di Jean-Louis PАUтRот (Pascal Quignard, Gallimard, 2013, con antologia di testi, illustrazioni, cronologia, bibliografia e cd audio contenente gli entretiens con Alain Veinstein, 1978-2012) e il penetrante studio di Agnès CoUSIN DE RAVEL sulla lettura come segreto condiviso della scrittura (Quignard, maitre de lecture. Lire, vivre, écrire, Hermann, 2012). Nel correlare fra loro danza e scrittura-lettura in quanto espressioni di un medesimo desiderio e di un'analoga «descente en soi» (p. 39), Agnès Cousin de Ravel instaura del resto un dialogo critico con Chantal Lapeyre-Desmaison. A questi volumi andranno presto ad aggiungersi gli atti delle sessioni dedicate all'autore durante il 20th and 21st Centuries French and Francophone Studies International Colloquium di Atlanta (28-30 marzo 2013), di cui è stato ospite, e quelli del convegno Les Lieux de Pascal Quignard tenutosi il 29 e 30 aprile 2013 presso l'Université du Havre. 